Relations industrielles

Industrial Relations

\title{
The Evolution of Wage Structure, by L.G. Reynolds and C.H. Taft, New Haven: Yale University Press, 1956, 399 pp.
}

J.S.

Volume 14, numéro 2, avril 1959

URI : https://id.erudit.org/iderudit/1022331ar

DOI : https://doi.org/10.7202/1022331ar

Aller au sommaire du numéro

Éditeur(s)

Département des relations industrielles de l’Université Laval

ISSN

0034-379X (imprimé)

1703-8138 (numérique)

Découvrir la revue

Citer ce compte rendu

S., J. (1959). Compte rendu de [The Evolution of Wage Structure, by L.G. Reynolds and C.H. Taft, New Haven: Yale University Press, 1956, 399 pp.] Relations industrielles / Industrial Relations, 14(2), 310-310.

https://doi.org/10.7202/1022331ar

Tous droits réservés (C Département des relations industrielles de l’Université Laval, 1959
Ce document est protégé par la loi sur le droit d'auteur. L’utilisation des services d'Érudit (y compris la reproduction) est assujettie à sa politique d'utilisation que vous pouvez consulter en ligne.

https://apropos.erudit.org/fr/usagers/politique-dutilisation/ 
of a buffer zone of semi-political positions between the fully political positions at the top and the upper ranks of the non-political career service.

The authors recognize that none of the four above-mentioned issues can be settled in isolation from some sets of conceptions about the party system and its relation to the conduot of the government, including conceptions about the role of the Chief Executive.

EMILE Gosselin

The Evolution of Wage Structure, by L.G. Reynolds and C.H. Taft, New Haven: Yale University Press, 1956, $399 \mathrm{pp}$.

Le livre se distingue par la clarté de son plan et le succès avec lequel on l'a suivi. Trop souvent les espoirs d'un plan précis sont noyés dans la confusion des chapitres qui suivent. C'est là un reproche que l'on ne peut porter à l'égard des auteurs de ce volume: l'intelligence de la présentation est soutenue tout le long du volume.

On y retrouve deux parties principales. L'une traite de l'évolution de la structure des salaires dans quatre industries américaines; l'autre offre une étude comparative de la détermination et de la structure des salaires dans cinq pays différents, la France, la Suède, la Grande-Bretagne, le Canada et les Etats-Unis.

L'objectif des auteurs est de déterminer l'influence des unions dans l'évolution de la structure des salaires. C'est là un objectif difficilement réalisable. La structure des salaires change continuellement et la responsabilité de l'union dans ces changements est mêlée à celles des autres facteurs économiques - qui, eux aussi, changent continuellement. Les auteurs ont cru, cependant, qu'en rapprochant de l'union les changements dans la structure des salaires, on pouvait produire certaines conclusions raisonnables.

L'étude n'aboutit pas à une «nouvelle » théorie des salaires: ce n'était pas là l'intention des auteurs. Elle précise, en les quantifiant, les changements qui ont pris place dans les différences de salaires qui existent d'une occupation à l'autre, d'une industrie à l'autre, d'une région à l'autre et ce, au cours des deux dernières décades, dans les pays déjà mentionnés plus haut.

On trouve à la fin du volume une intéressante appréciation des sounces statistiques utilisées.

J.S.

\section{PUBLICATIONS RECENTES RECENT PUBLICATIONS}

\section{Généralités}

«Chronique du language technique 》, par Ch. Voraz, Travail et Méthodes, Paris, no 129, décembre 1958, pp. 4346.

«Le manché commun », Bulletin Social des Industriels, Bruxelles, Belgique, $30 \mathrm{e}$ année, no 252 , décembre 1958 , pp. 445469.

- Commentaire de Radio-Vatican \$, pp. 445-446.
- Les institutions européennes, expression de la solidarité de l'Europe »; par W. Hallstein, pp. 447-450.

—Le comité économique et social: à la lueur des textes », pp. 451-452.

- Le comité économique et social 》, par M. Masoin, pp. 453-455.

- \& L'examen de conscience du chef d'entreprise face au marché commun $\gg$, par J. Paridant de Cauwere, pp. $456-463$. 